\title{
LA DEBILIDAD DE LAS SÚPER-MAYORÍAS
}

[The Weakness of Supermajorities]

\author{
Guillermo JimÉneZ* \\ PABlo MaRshall ${ }^{* *}$ \\ Universidad Austral de Chile \\ FERnANDo MuÑoz ${ }^{* * *}$ \\ Universidad Austral de Chile
}

RESUMEN

Este artículo constituye una réplica a la defensa del sistema de súper-mayorías que establece la Constitución chilena, recientemente publicado por Sergio VERDUGo. Tras verificar un empate entre las razones a favor y en contra de las súper-mayorías en el plano de la justificación general, Verdugo propone pasar a discutir cada una de las reglas de quórum calificado en específico. Este artículo

\section{ABstract}

This article replies to the defense of the supermajority system established in the Chilean Constitution, recently published by Sergio Verdugo. After verifying a tie between the reasons in favor and against supermajorities in the scope of general justification, Verdugo proposes starting to discuss specifically each of the rules for qualified quorum. This article rebuts both Verdugo's strategy and his

RECIBIDO el 28 de junio y ACEPTADo el 30 de noviembre de 2013

* Licenciado en Ciencias Jurídicas por la Universidad de Chile; LLM por el University College London. Correo electrónico: g.jimenez@ucl.ac.uk

** Licenciado en Ciencias Jurídicas por la Universidad de Chile; profesor de Derecho en la Universidad Austral de Chile; doctorando en la Universidad de Glasgow. Correo electrónico: pmarshall@uach.cl

*** Licenciado en Ciencias Jurídicas por la Universidad Católica de Chile; profesor de Derecho en la Universidad Austral de Chile; LLM por la Universidad de Yale; doctor por la Universidad de Yale. Dirección postal: Facultad de Derecho, Universidad Austral, Campus Isla Teja sin número, Valdivia, Chile. Correo electrónico: fernando. munoz@uach.cl 
rebate tanto la estrategia de Verdugo como sus argumentos generales y especiales para justificar las reglas de quórums súper-mayoritarios. El telón de fondo de este artículo está dado por una defensa de la conexión entre mayoría simple y democracia.

\section{Palabras Clave}

Súper-mayoría - Democracia - Igualdad política. general and special argumentation to justify the rules for supermajority quorums. The background of this article is made up by a defense of the link between simple majority and democracy.

KEYWORDS

Supermajority - Democracy - Political equality

\section{INTRODUCCIÓN}

En un artículo publicado recientemente en esta revista ${ }^{1}$, Sergio Verdugo ha efectuado una defensa de la súper-mayoría como regla para adoptar decisiones legislativas. En particular, su argumento está dirigido a defender a las leyes orgánicas constitucionales (en adelante "loc.s" o “loc.”). Esta posición es aparentemente más restringida que la tradicionalmente adoptada por autores conservadores en Chile. Él admite que el sistema de súper-mayoría debe ser acotado y excepcional. Tal sistema es legítimo si se restringe sólo a las materias "fundamentales". Por lo tanto, la discusión razonable -según Verdugo- no debería centrarse en la abolición del sistema de súper-mayoría, sino en la selección de las pocas materias fundamentales que ese sistema debería abarcar. Pareciera que concede implícitamente que las materias actualmente regidas por súper-mayoría son excesivas. Por esa razón -afirma- sería "razonable" discutir (por primera vez) cuál es el alcance de las súper-mayoría, en vez de discutir el sistema de súper-mayoría en sí mismo. Verdugo sostiene que los críticos de las "loc.s" se han concentrado en atacar su existencia, su justificación abstracta, y han descuidado el plano en que es más relevante entender y justificar dichos quórum, el plano de la regulación específica que se pretende extraer de la decisión de la mayoría. Así, su artículo examina algunas de las críticas generales, desestimándolas en base a otros tantos argumentos generales, para luego sostener que dado que hay razones generales a favor y en contra de las súper-mayorías, ellas se encuentran en un equilibrio argumentativo, por lo que lo adecuado es abandonar el nivel

${ }^{1}$ Verdugo, Sergio, Las justificaciones de la regla de quórum supra-mayoritario de las leyes orgánicas constitucionales, en Revista de Derecho de la Pontificia Universidad Católica de Valparaíso, 39 (Valparaíso, 2012). 
de la justificación general y dirigirlo hacía la justificación especial de cada materia de "loc."

Si bien esta posición en términos de transigencia al dialogo tiene que ser vista como un avance, los argumentos que se ofrecen para aceptar un sistema de súper-mayoría no son persuasivos y es importante responderlos. La defensa de las "loc.s", como se argumentará, sólo tiene cabida en un sistema de pensamiento conservador, que no cree en la democracia como forma de gobierno y que se siente cómoda con el legado institucional de la dictadura.

En vistas a la importancia de la materia en cuestión, nos ha parecido pertinente visitar un género que está lamentablemente ausente en nuestra comunidad académica: el de la réplica. El artículo de Verdugo está bien referenciado y muestra cierta apertura al dialogo, realizando una exhaustiva revisión de la literatura nacional sobre el asunto ${ }^{2}$, todo lo cual permite establecer esta relación dialógica.

En este artículo, siguiendo la estructura del artículo que se critica, se abordan tanto los problemas generales como los problemas especiales relativos a las "loc.s". Así, se contesta la idea de que el debate actual en la literatura chilena sobre súper-mayoría está mal llevado. Se sostiene que la forma de la estrategia delata su debilidad. Es equivocado querer dirigir la discusión hacia la justificación específica de las "loc.s" porque en el nivel general las razones estarían equilibradas. Al contrario, en el nivel de los argumentos generales las razones hablan abrumadoramente, desde una perspectiva democrática, a favor de la eliminación de las "loc.s" de nuestra Constitución. Los problemas que Verdugo ve en las críticas a las súper-mayorías obedecen a sus propios problemas para entender y analizar desde un punto de vista democrático las "loc.s". Acá consideramos que la tesis de la justificación especial no es más que una estrategia dilatoria. Para demostrar, esto la sección II que sigue a esta introducción se detiene en argumentar 5 puntos críticos: $i$ ) que la regla

${ }^{2}$ Véase: MuÑoz, Fernando, Leyes Orgánico-constitucionales. Insatisfactoria rigidización de la democracia, en Anuario de Derecho Constitucional Latinoamericano, 1 (2006); Atria, Fernando, Participación y alienación politica: el problema constitucional, en Fuentes, Claudio (editor), Nombre del pueblo: debate sobre el cambio constitucional en Chile (Santiago, Heinrich Böll Stiftung - ConoSur e ICSO Diego Portales, 2010); Couso, Javier - Coddou, Alberto, Las asignaturas pendientes de la reforma constitucional chilena, en Fuentes, Claudio (editor), en Nombre del pueblo: debate sobre el cambio constitucional en Chile (Santiago, Heinrich Böll Stiftung - ConoSur e ICSO Diego Portales, 2010); Sierra, Lucas - MAC-Clure Lucas, Frente a las mayorías: leyes supramayoritarias y Tribunal Constitucional en Chile (Santiago, Centro de Estudios Públicos, 2011); Szmulewicz, Esteban, Democracia, gobierno de la mayoria y leyes orgánicas constitucionales. Parte I (Santiago, Asuntos Públicos, Informe 954, 2012-I) [visible en internet: http://www.asuntospublicos.cl/wp-content/uploads/2012/04/954. pdf] 
de mayoría es la regla de decisión democrática por defecto; $i i)$ que no puede obviarse el origen de las "loc.s" pues este sí afecta su carácter democrático en el contexto en que esta discusión se produce; iii) que la estrategia de Verdugo altera la carga de la argumentación sobre la modificación de las "loc.s" desde una carga de argumentación democrática, en que quienes deben satisfacerla son quienes quieren alterar el régimen mayoritario, a una carga de argumentación basada en el status quo, en la cual quienes quieren cambiar una institución, independiente de su carácter antidemocrático, deben sobrepasar exigentes tests de justificación teórica; iv) que los ejemplos de derecho comparado que Verdugo emplea en su justificación de la regla de súper-mayoría son infértiles. Finalmente, $v$ ) se sostiene que, pese a que las súper-mayorías podrían cumplir algún rol legítimo en una democracia constitucional, esto es imposible de entender cuando, como en Chile, existe una súper-población de mecanismos contra-mayoritarios.

La segunda parte del artículo, desarrollada en la sección III, se ocupa del argumento central del artículo de Verdugo consistente en que la justificación de las "loc.s" debe hacerse en el nivel de la regulación particular de ciertas materias, entendiendo éstas como necesitadas de quórum reforzado. Sin perjuicio que en la sección II se evidencia que esta estrategia no sólo es equivocada sino que además busca desviar el foco de la discusión, en esta sección se examinan y descartan las supuestas justificaciones especiales a favor de las "loc.s" Argumentando en el nivel específico, y examinando cada una de las defensas que se presentan, se descarta la justificación específica de cada una de ellas. Ello se hace, algunas veces mostrando que los argumentos específicos son ingenuos, en otras mostrando que son en realidad argumentos generales reiterados a nivel específico.

\section{LA JUSTIFICACIÓN GENERAL DE LAS SÚPER-MAYORÍAS COMO QUÓRUM DE DECISIÓN EN EL PROCESO LEGISLATIVO}

\section{La justificación de la regla de la mayoría.}

Conviene comenzar recordando que la justificación de la regla de la mayoría simple consiste en que es la única regla de decisión que respeta la igualdad política y la democracia ${ }^{3}$. La conexión entre mayoría, igualdad política y democracia es bien conocida y sencilla. Los críticos de las súpermayorías son ante todo defensores de la mayoría simple como mecanismo de súper-mayoría o para la toma de decisiones legislativas. En virtud de este

${ }^{3}$ Para una clásica defensa de la regla de la mayoría: DAHL, Robert, Democracy and its Critics (Yale University Press, 1989), pp. 139-141. Véase, recientemente: DAHL, Robert, On Political Equality (Yale University Press, 2006), p. 15. 
último procedimiento, la opinión política de cada uno de los ciudadanos pesa lo mismo que la súper-mayoría o que la opinión de cualquiera de los demás. En otras palabras, no deben existir ciudadanos cuyo voto valga más que el de los demás

De esta manera, la justificación de la regla de mayoría simple (o de "una persona, un voto") es que ella es la expresión técnica de la igualdad política de los ciudadanos. La regla de mayoría simple le da a cada uno de los participantes en la decisión la posibilidad de tomar parte en ella en la misma medida que todos los demás 5 . Así, la principal justificación para la regla de mayoría simple se relaciona con la imparcialidad del proceso ("inputs"), más que con los resultados que ella produce ("outputs"), respecto de los cuales es neutral. En efecto, la regla de mayoría es valiosa en sí misma, sin necesidad de evaluar las finalidades o resultados que producirá con mayor o menor probabilidad ${ }^{6}$. Waldron expresa esta idea de la siguiente forma: "Mejor que cualquier otra regla, la regla de mayoría, es neutral entre resultados controvertidos, trata a los participantes igualitariamente, y concede a cada opinión que se formule el mayor peso posible que sea compatible con otorgar igual peso a todas las opiniones"7.

Verdugo pasa por alto la explicación anterior. Si bien en su artículo señala que la mayoría simple debe ser la regla general y que la súper-mayoría la excepción ${ }^{8}$, su aceptación de la regla de mayoría simple no pareciera justificarse en las consideraciones anteriores; esto es, en ser el único sistema que no vulnera el principio de igualdad política. Lamentablemente, él no explica el fundamento de su preferencia parcial o meramente prima facie por la regla de mayoría simple.

Por otro lado, en su trabajo Verdugo coquetea con dos ideas que expresan desacuerdo con la idea de que la regla de mayoría como expresión de la igualdad política es la regla de decisión democrática. Primero, señala que "el ideal democrático es la unanimidad", pero que consideraciones pragmáticas aconsejan aceptar las súper-mayorías como "punto medio". Esa concepción

${ }^{4}$ Cf. Sierra, Lucas - Mac-Clure, Lucas, cit. (n. 2), pp. 14-16.

${ }^{5}$ Waldron, Jeremy, The Core Case Against Judicial Review, en Yale Law Journal, 115 (2006), pp. 1.347, 1.387 ss.; Bellamy, Richard, Citizenship. A Very Short Introduction (Oxford University Press, 2008), p. 110.

${ }^{6}$ Lo anterior es cierto tanto a nivel de ciudadanos como de parlamentarios, porque la acción combinada de la aplicación de la regla de mayoría en ambos niveles hace que los valores de igualdad e imparcialidad tengan lugar al menos aproximadamente respecto de la ciudadanía como un todo: WALDRON, Jeremy, cit. (n. 5), pp. 1.388-1.389

${ }^{7}$ WALDRON, Jeremy, cit. (n. 5), p. 1.388.

${ }^{8}$ Verdugo, Sergio, cit. (n. 1), p. 406.

${ }^{9}$ Verdugo, Sergio, cit. (n. 1), p. 408. Sin perjuicio de que Verdugo no lo señale explícitamente allí, parece claro que su referencia implícita es a la formulación teórica 
de la democracia está basada lisa y llanamente en dos mal entendidos. El primero es la confusión de los conceptos de consenso (consensus) y acuerdo ("agreement"). Mientras el primero implica un entendimiento racional de los participantes que toman una decisión colectiva como resultado de un proceso discursivo en que todos los intereses y puntos de vista han sido debidamente considerados y todos los afectados incluidos, el segundo está abierto a la incorporación de consideraciones puramente instrumentales en una negociación por parte de grupos que no buscan definir una forma de vida común sino acomodar intereses contrapuestos.

El consenso es una forma democrática de alcanzar la unanimidad dado que la igualdad política es respetada en el proceso discursivo. Sin embargo, no podemos adoptar como modelo para la toma decisiones la idea del consenso, pues éste es alcanzado, no acordado ni decidido. Hay consenso sólo cuando, satisfechos los supuestos en cuestión, efectivamente se ha llegado a consenso; no lo hay cuando subjetivamente deseemos haberlo alcanzado, ni cuando institucionalmente afirmemos haberlo alcanzado ${ }^{10}$. Por esto, lo que tenemos en una democracia constitucional es un modelo de acuerdos ${ }^{11}$.

Esto nos lleva a la segunda confusión, que es el rol que juega la unanimidad en el contexto del consenso y de los acuerdos. En el primer caso, si la unanimidad se ha logrado por consenso eso involucrará un nivel de entendimiento colectivo respecto a esa materia que no hace necesaria una decisión al respecto.

de Buchanan - Tullock en The Calculus of Consent. Logical Foundations of Constitutional Democracy (Liberty Fund, 1999), esp. cap. $7^{\circ}$. Esta es una comprensión de la democracia que: $i$ ) no se hace cargo de las consecuencias perjudiciales para la igualdad política de los ciudadanos del requerimiento de unanimidad; y ii) que no es capaz de diferenciar los intereses, una preocupación clásica del diseño constitucional, del desacuerdo moral, una variable cuya relevancia para el diseño constitucional ha sido enfatizada por Waldron. Para una crítica a Buchanan y Tullock, véase: SHAPIRO, Ian, The Moral Foundation of Politics (Yale University Press, 2003), pp. 214-217; SADURSKI, Wojciech, Equality and Legitimacy (Oxford, Oxford University Press, 2008), pp. 60 ss. Para el análisis del impacto del desacuerdo moral en las instituciones democráticas, véase: Waldron, Jeremy, Law and Disagreement (Oxford, Oxford University Press, 1999), esp. pp. 105-118.

${ }^{10}$ Por esto Nino plantea que la democracia encuentra su valor en ser un sucedáneo del discurso moral; el cual, a su juicio, tiene valor propio, pero debido a su carácter incesante no nos permite adoptar decisiones cuando ellas son necesarias e impostergables: Nino, Carlos, Ética y derechos humanos (Buenos Aires, Astrea, 1989) pp. 387 ss.

${ }^{11}$ Habermas, Jurgen, Between Facts and Norms (London, Polity Press, 1996), pp. 176-86. Desde luego, nada tiene que ver esta afirmación teórica con la existencia de una "democracia de los acuerdos" al estilo implementado en Chile durante los años ' 90. Para una crítica a la formulación anglo-americana de la "democracia de los acuerdos" véase: Mouffe, Chantal, The Return of the Political (London, Verso, 2005) esp. 1-8, y de la misma autora, The Democratic Paradox (New York, Verso, 2005), esp. 80-128. 
Pero aquí la unanimidad es entendida como la expresión del consenso, no como un requerimiento de acuerdo. En el contexto de los acuerdos, esto es, en el nivel de nuestra práctica política cotidiana, la unanimidad juega el rol de una regla para adoptar acuerdos, una cuyas implicaciones están en las antípodas del consenso. Por un lado, ella elimina todo incentivo de acuerdo racional y, por otro, empodera a quienes amparados en la regla de decisión son favorecidos en sus intereses con el mantenimiento del status quo. En contraposición, la regla de la mayoría concede igual poder de decisión a todos, conforme a los postulados de la igualdad política.

La asimetría entre consenso y decisión por unanimidad se hace patente cuando se observa que el consenso respeta tanto la igualdad política de todos y cada uno de sus integrantes como la libertad de todos como comunidad, mientras la decisión por unanimidad sólo garantiza que ninguno de los sujetos involucrados va a verse forzado por una decisión que él no ha aceptado ${ }^{12}$. Esto, en la práctica, significa que sólo respeta a quienes están interesados en el mantenimiento del estado de cosas existente; lo que, a la luz del modelo de racionalidad instrumental canónico en la teoría de la elección racional, sugiere que están interesados en el mantenimiento de su propio privilegio. Por tanto, aunque resulte paradójico, en ausencia de consenso - esto es, cuando tenemos que decidir mediante acuerdos-, la mejor regla, aquella que mejor respeta los intereses de todos, no es aquella de la unanimidad sino que la de mayoría. Así, otro tanto vale para aquellas reglas de decisión que apelando al ideal de la unanimidad argumentan que mientras mayor el quórum de decisión, más democrática será la norma acordada conforme con él.

Ahora bien, eso lleva a la segunda cuestión; esto es, la pregunta sobre si la mantención del statu quo tiene valor en sí mismo y, por tanto, si debe recibir protección frente la opción opuesta, el cambio ${ }^{13}$. Una respuesta basada en los principios de igualdad política y pluralismo político como bases de la democracia tiene que necesariamente responder negativamente a esta pregunta. Una regla de súper-mayoría trata desigualmente a quienes quieren cambiar respecto de quienes quieren oponerse al cambio. Estos últimos son favorecidos ${ }^{14}$. Por el contrario, entender la regla de mayoría pasa también por reconocer que ésta no es contraria al statu quo, sino que simplemente es neutral ${ }^{15}$. La idea de la protección del statu quo sólo puede provenir de

${ }^{12}$ SADURSKI, Wojciech, Equality and Legitimacy, cit. (n. 9), p. 60.

${ }^{13}$ Sobre la idea de la democracia protegida, hay abundante material en el volumen editado por Fuentes, Claudio (editor), En nombre del pueblo: debate sobre el cambio constitucional en Chile (Santiago, Heinrich Böll Stiftung - ConoSur e ICSO Diego Portales, 2010).

${ }^{14}$ SAdURSKI, Wojciech, cit. (n. 9), pp. 60-61

${ }^{15}$ La mantención del statu quo es importante aunque en una forma bastante distin- 
la creencia en la constitución no como un conjunto de principios básicos que estructuran el auto-gobierno democrático, sino como un conjunto de mecanismos de protección de los intereses individuales frente a la intervención del estado ${ }^{16}$. Sin embargo, dicha concepción no toma en cuenta que el disfrute de dichos intereses sólo es posible mediante la protección que el derecho les brinda, eludiendo confrontar seriamente la pregunta de por qué debemos dificultar mediante reglas súper-mayoritarias la revisión democrática de dichos mecanismos jurídicos ${ }^{17}$. La respuesta sólo puede ser que dichos arreglos institucionales súper-mayoritarios no cumplen el objetivo de dar continuidad al sistema jurídico, o proteger los intereses individuales necesarios para el autogobierno individual y colectivo, sino que cumplen la (injustificada) función de impedir que el pueblo pueda revisar la práctica legal existente y cambiarla, en un ejemplo de lo que Böckenförde llama una "revolución legal"18. No puede sino presumirse que dicha desconfianza hacia la revisión democrática se debe a que los arreglos institucionales que dificultan la acción del legislador son expresión de un juego en el que las cartas han sido mal repartidas; en el que algunos han sido beneficiados más que otros. Esta presunción se hace aún más plausible cuando las reglas que

ta de la que Verdugo propone. Existe una aspiración de continuidad institucional tanto política como jurídica que no puede depender del constante acuerdo de los distintos actores involucrados sino que proyecta su pretensión de vigencia hacia el futuro. Típicamente la vigencia permanente de las normas jurídicas hasta que otra norma jurídica derogue dicha vigencia es una expresión de la protección del statu quo. Sin embargo, esta expresión del statu quo es suficientemente protegida mediante un procedimiento de decisión mayoritaria. En este sentido, De Oтto, Ignacio, Derecho constitucional. Sistema de fuentes (Barcelona, Ariel, 1988), p. 60, sostiene que la necesidad de una primacía del statu quo sobre la innovación sólo está justificada para cautelar la integridad del orden jurídico, mediante el establecimiento del principio de la decisión por mayoría por sobre del principio de equivalencia de las opciones: "En efecto, cuando se vota un proyecto de ley, esto es, acerca de la innovación del ordenamiento, el principio de equivalencia requeriría que tanto el proyecto como la oposición al mismo necesitasen la misma mayoría para triunfar, lo que supondría que ambos se sometiesen a votación y que para ambos se exigiese la mayoría de los votos emitidos. Sin embargo no ocurre así sino que, derrotado el proyecto por no haber obtenido la mitad más uno de los votos, sino por ejemplo, solo la mitad, no es preciso votar por la continuidad de la norma, que se produce por el simple hecho de no haber prosperado la opción reformadora”.

${ }^{16}$ Tres razones podrían esgrimirse para esto. El statu quo: $i$ ) asegura el conocimiento de la ley; ii) garantiza mejor las expectativas legales; y iii) protege frente a los efectos imprevistos del cambio [SADURSKI, Wojciech, cit. (n. 9), p. 65].

${ }^{17}$ Sunstein, Cass, The Partial Constitution (Cambridge, Harvard University Press, 1993), p. 6.

${ }^{18}$ BÖCKENFÖRDE, p. 80 
determinaron dichas instituciones legales fueron dictadas en un momento en que la democracia en Chile se encontraba suspendida.

\section{El origen antidemocrático de las leyes orgánicas constitucionales.}

El análisis de Sergio Verdugo deliberadamente no toma en cuenta parte importante de la crítica a las "loc.s", específicamente aquella que denuncia la ilegitimidad de su origen. Pero, como mostraremos a continuación, pasar por alto este aspecto del debate resulta inaceptable.

Según Verdugo, los críticos sostendrían que "con la creación de las leyes org. const., el régimen militar habría buscado dificultar las reformas a la estructura de su sistema constitucional, protegiendo la 'idea guzmaniana de democracia protegida', lo que habría sido producto de la desconfianza que dicho régimen habría tenido hacia las mayorías" ${ }^{\prime 19}$.

Verdugo contesta esta crítica afirmando que esta posición confunde "el argumento político frente al origen de la norma con las consecuencias de la misma". Aparentemente, esta respuesta se basa en el deseo de juzgar el mérito de las "loc.s" como un instrumento constitucional que podría ser usado en contextos distintos al de la dictadura. Por ejemplo, este punto de vista insensible al contexto serviría para "discutir la inclusión de nuevas leyes org. const." ${ }^{20}$. Por eso concluye que su propuesta no analiza el problema del origen político de las "loc.s". En cambio, su interés es "aislar la justificación y los beneficios de ellas" ${ }^{21}$.

Verdugo efectúa la misma exclusión en un trabajo anterior en donde afirma que no analizará el "supuesto pecado de origen que se ha invocado para deslegitimar las misas, en cuanto ellas fueron creadas por el Gobierno Militar". Él agrega que "[s]e trata de un argumento de autoridad (sic) que no ataca necesariamente las razones para establecer reglas de súper-mayorías en materia legislativa" 22 . En esa ocasión, sin embargo, demuestra una curiosa forma de entender el problema de la "ilegitimidad de origen". Él sostiene que “esta objeción del 'pecado de origen' comienza en la propia CENC, donde algunos miembros de ella (Guzmán, Ortúzar, Lorca y Carmona) manifestaron sus temores a que, debido al alto quórum de aprobación de las mismas, ellas podrían correr el riesgo de que nunca fueran dictadas, dejando un vacío insalvable en la Constitución" ${ }^{23}$.

Como se ve, Verdugo pareciera entender que el pecado de origen de las

\footnotetext{
${ }^{19}$ Verdugo, S., cit. (n. 1), pp. 401-402 (citas internas omitidas).

${ }^{20}$ Ibíd.

${ }^{21}$ Ibíd.

${ }^{22}$ Verdugo, Sergio, Regla de mayoría y democracia: el caso de las leyes orgánicas constitucionales en Actualidad Jurídica, 20 (Santiago, 2009) 2, pp. 600-601.

${ }^{23}$ Verdugo, Sergio, cit. (n. 22).
} 
"loc.s". consiste en que, por su alto quórum, ellas podrían nunca ser dictadas. Esa versión de la crítica está evidentemente mal formulada. Afortunadamente, en su posterior versión él entiende mejor que los críticos acusan que las "loc.s" fueron un instrumento de la dictadura militar para impedir que gobiernos posteriores modificaran aspectos esenciales de la organización de la comunidad política, tales como el sistema electoral, el sistema educacional, el Tribunal Constitucional, la distribución del poder territorial, entre tantos otros. No obstante, su error en torno al alcance de la crítica sobre el origen se mantiene.

A pesar de que la discusión abstracta que propone Verdugo puede ser teóricamente interesante, la verdad es que no es esa la discusión que tiene lugar actualmente en la comunidad jurídica y política chilena. Como él mismo señala, “[e]l objeto de [la] crítica ha sido el sistema de leyes orgánicas constitucionales [...] establecido entre nosotros por el constituyente de 1980". En otras palabras, la discusión en Chile es contextualizada e histórica, no abstracta y atemporal. Por eso, los argumentos de Verdugo no son pertinentes para la discusión chilena, salvo que se entiendan como argumentos sobre cómo deberíamos diseñar el régimen de adopción de legislación en una nueva Constitución. Pero ese no parece ser el propósito de Verdugo.

Por lo demás, el problema del origen es inescapable para una defensa de los quórum calificados. En efecto, la defensa de las súper-mayorías se basa normalmente en una valoración favorable del statu quo. Como señalan Goodin y Lins: "Las reglas de mayorías calificadas dejan vigente el orden existente al menos que exista una decisión positiva que lo cambie. De ahí que tales reglas tengan un poderoso sesgo conservador. Esa es precisamente su atracción, para aquellos atraídos por ellas. Así, justificar las reglas de mayorías calificada parece ser en una importante medida un asunto de justificar el sesgo conservador" 24 .

De este modo, para juzgar las súper-mayorías de la Constitución chilena vigente resulta inevitable realizar un juicio de valor sobre el estado de cosas que pretender proteger. En una importante medida, el rechazo a las "loc.s" es precisamente un rechazo a un régimen de votación legislativo que favorece un statu quo democráticamente inaceptable.

El contexto, entonces, no puede ser indiferente a la hora de discutir sobre mayorías calificadas. Por ejemplo, si se discute si son deseables las súpermayorías para adoptar decisiones en un proceso penal, no pareciera existir nada en contra de que sólo mediante ellas se adopte una decisión de condena. En ese caso, un sesgo a favor del status quo, esto es, de la presunción de ino-

${ }^{24}$ Goodin, Robert - Lins, Christian, Special Majorities Rationalized, p. 1 [disponible en http://personal.lse.ac.uk/list/PDF-files/SplMaj1508.pdf]. 
cencia, no resulta particularmente reprochable ${ }^{25}$. Sin embargo, si lo es exigir súper-mayorías para poder modificar los arreglos legales de una dictadura.

Por otra parte, Verdugo pareciera quedarse con lo conveniente y rechazar lo inconveniente de la teoría de las súper-mayorías. Uno de los argumentos para defender las súper-mayorías consiste en sostener que una legislación aprobada según ellas, en ciertas circunstancias puede ser de mejor calidad que una aprobada bajo un régimen de mayoría simple. Rappaport y McGinnis, por ejemplo, usan ese argumento para defender una interpretación supermayoritaria de la Constitución de Estados Unidos. ${ }^{26}$ Aunque el argumento general de estos autores no resulta convincente, acá basta destacar que su punto de partida es la aprobación por súper-mayoría de la propia Constitución estadounidense. Así, defienden la súper-mayoría, pero la vinculan a una visión originalista de la Constitución ${ }^{27}$. Ellos afirman que: "el hecho de que la constitución original y sus reformas tuvieran que satisfacer reglas de estricta súper mayoría ha hecho de la constitución un documento de mucha mayor calidad de lo que sería si hubiera sido aprobado por un mera mayoría" ${ }^{28}$.

En Chile, sin embargo, ni las reglas constitucionales que exigen súpermayorías, ni las "loc.s" aprobadas durante las dictaduras fueron aprobadas por súper-mayorías. Ninguna de esas reglas, entonces, pueden alegar tener mayor calidad que las reglas aprobadas por mayoría simple. Todas esas reglas fueron aprobadas sin pasar ningún test de mayoría, sea simple o calificada. Por eso, resulta incomprensible invocar argumentos "abstractos" sobre los supuestos beneficios de las súper-mayorías para justificar tales reglas. En definitiva, ninguna de las supuestas virtudes de las súper-mayorías en términos de protección de minorías y de satisfacción del interés público puede ser predicada de las reglas del sistema constitucional chileno impuesto por la dictadura. Una dictadura es el lugar ideal para diseñar reglas que aseguren que facciones y grupos de interés capturen las instituciones y dañen el interés público. Por lo tanto, no es razonable defender con quórums calificados el statu quo que esas reglas protegen.

Como hemos visto, el rechazo de Verdugo a discutir sobre el origen de las "loc.s" es inaceptable. En primer lugar, porque la crítica legitimista contra las súper-mayorías es contextualizado, ya que se refiere a las reglas constitucionales y legales impuestas por la dictadura. Además, cualquier defensa de las mayorías calificadas supone una valoración positiva del statu

${ }^{25}$ Goodin, Robert y Lins, Christian, cit. (n. 24).

${ }^{26}$ Rappaport, Michael - McGinnis, John, Our Supermajoritarian Constitution (San Diego, University of San Diego, Public Law and Legal Theory Working Paper 37).

${ }^{27}$ Ibíd., p. 90.

${ }^{28}$ Ibíd., p. 85. 
quo. Si bien en algunos contextos eso puede ser aceptable, en la discusión constitucional chilena no lo es. Además, si bien en otros países la defensa del statu quo constitucional se basa en que las normas que lo forman fueron aprobadas por mayorías calificadas, ese argumento no puede ser invocado para defender el régimen impuesto por la dictadura en Chile.

\section{Alterando la carga de la prueba.}

En general, la defensa de las "loc.s" por parte de Sergio Verdugo se construye atacando las supuestas debilidades de las posturas de los críticos de ese régimen de votación. Sigue esa estrategia, por ejemplo, cuando ataca la conexión que existe entre democracia y regla de mayoría. Así, identifica dos críticas a las "loc.s" que afirman que ellas atentan contra principios democráticos. Por un lado, las "loc.s" impedirían a los gobiernos democráticos avanzar sus agendas ${ }^{29}$. Por otro lado, las "loc.s" violarían "el valor individual de cada voto parlamentario, con lo que se alteraría la igualdad de voto que toda democracia representativa supone" 30 .

La respuesta de Verdugo es que a estas críticas les hace falta un análisis del resto de los instrumentos contra-mayoritarios que posee la Constitución (véase, más abajo, II,5). Además, afirma que no es cierto que toda democracia necesite adoptar todas sus decisiones legislativas por mayoría simple (véase, más arriba, II,1). Por último, sostiene que para defender su tesis los críticos deben explicar previamente qué materias debe tener una constitución y qué materias deben ser reguladas por la legislación ${ }^{31}$. Como se ve, su estrategia consiste en traspasar la carga argumentativa a quienes critican las "loc.s" Pareciera aprovecharse del hecho de que la Constitución ya exige súper-mayorías y que las "loc.s" ya están dictadas. En otras palabras, aprovecha que el statu quo beneficia su posición. Por eso, su estrategia consiste en exigir a los críticos que elaboren una teoría compleja y comprehensiva de la democracia constitucional antes de poder sentarse a discutir sobre la legitimidad de las "loc.s" Así, sugiere que mientras los críticos no sean capaces de elaborar tal teoría, debemos aceptar las "loc.s" y sólo discutir los casos específicos en que ellas tendrán lugar.

Sin embargo, adoptar esa estrategia es injustificado. El punto de partida de la discusión debe ser los procedimientos mayoritarios, no los súper-mayoritarios. Hannah Arendt alguna vez sostuvo que el principio de mayoría era inherente al proceso mismo de toma de decisiones y que era probable que

\footnotetext{
${ }^{29}$ Ibíd., p. 402.

${ }^{30}$ Ibíd., p. 403.

${ }^{31}$ Ibíd., pp. 404-405.
} 
fuera adoptado casi automáticamente en todo tipo de decisiones colectivas ${ }^{32}$. Por supuesto, esto no significa que esta intuición no pueda ser sometida a examen, pero al menos debe reconocerse que cuando discutimos sobre procedimientos democráticos, las decisiones por mayoría tienen una posición de ventaja por defecto; resultan intuitivas para la lógica democrática. Por lo demás, las virtudes de la regla de mayoría en cuanto único sistema de votación que satisface exigencias de igualdad, neutralidad y de sensibilidad a los cambios en las preferencias de los votantes, vienen siendo reconocidas desde hace varias décadas ${ }^{33}$. Por lo tanto, no resulta razonable defender el statu quo favorable a las "loc.s" mientras los defensores de las decisiones mayoritarias elaboren una sofisticada teoría de la Constitución. Al revés, el argumento en contra de las "loc.s" consiste precisamente en afirmar que debemos tener mecanismos mayoritarios, salvo que quienes promueven mayorías calificadas sean capaces de probar su utilidad en contextos específicos. En un régimen democrático, la carga argumentativa está en contra de las mayorías calificadas, no en contra de las mayorías simples.

Este sesgo súper-mayoritario contamina gran parte de su propuesta. Esto es un problema porque, mientras un sesgo mayoritario es plausible, uno súper-mayoritario no lo es. Por un lado, es impensable un régimen democrático en que la legislación, por defecto, se adopte por súper-mayoría. Pero si es imaginable una democracia que no considere en absoluto reglas de súper-mayoría. Por otro lado, en su mejor versión las mayorías calificadas son un mecanismo de defensa de las minorías frente a las mayorías, ${ }^{34}$ pero como se ha visto no es el único. Por eso, es posible proteger a las minorías sin necesidad de súper-mayorías. En cambio, no es posible concebir un gobierno democrático sin que la legislación se adopte por mayoría por defecto.

Es cierto que se podría argumentar que en realidad no existe un sesgo súper-mayoritario en el trabajo de Verdugo. Ante el desacuerdo en el nivel general o abstracto, él simplemente estaría intentando buscar consensos en un nivel inferior. Su estrategia sería buscar "acuerdos incompletamente

${ }^{32}$ Arendt, Hanna, On Revolution, citado en Waldron, Jeremy, The Dignity of Legislation (Cambridge, Cambridge University Press, 1999), pp. 125-126.

${ }^{33}$ MAy, Kenneth, A Set of Independent Necessary and Sufficient Conditions for Simple Majority Decision, en Econometrica, 20 (1952). Se trata del artículo fundamental sobre este tópico.

${ }^{34}$ Vermeule, Adrian, Mechanism of Democracy. Institutional Design Writ Small (Oxford, Oxford University Press, 2007), discutiendo que las minorías podrían merecer protección cuando sus preferencias son inusualmente intensas, cuando son susceptibles de explotación y cuando poseen información especial que las mayorías querrían obtener (pp. 135 ss); Goodin, Robert - Lins, Christian, cit. (n. 24), discuten en qué circunstancias es deseable que un sistema de toma de decisiones otorgue veto a una minoría. 
teorizados"35. Así, él compartiría la intuición de Sunstein de que cuando la gente diverge respecto de proposiciones de nivel de abstracción relativamente alto, ellos son capaces de llegar a un acuerdo si disminuyen el nivel de abstracción.

A pesar de que esa estrategia podría ser razonable, ella no es la que utiliza Verdugo. No es que él identifique un desacuerdo en torno a la noción abstracta de democracia y quiera llegar a un acuerdo de bajo nivel sobre los sistemas de votación. Tampoco es que quiera evitar un desacuerdo abstracto sobre los sistemas de votación, llegando a un acuerdo en concreto sobre un sistema de toma de decisión concreto. Lo que él busca, en cambio, es que aceptemos que las "loc.s" deben tener un lugar en la Constitución a todo evento. Verdugo pretende eliminar por completo la discusión sobre su existencia y traducirla a una cuestión meramente cuantitativa. En su trabajo existen dos ejemplos de esto. En primer lugar, afirma que su propuesta permitiría discutir la inclusión de nuevas "loc.s", para eliminar algunas de ellas o reformular la manera en que ellas están redactadas. No es casualidad que su tesis no permita discutir la eliminación completa de la institución. Esa posibilidad está fuera de discusión. Para él no es posible que ninguna "loc." esté justificada en la Constitución vigente (véase, más abajo, III). En otras palabras, para él las "loc.s" son un statu quo protegido cuya extensión se puede discutir, pero que no se puede eliminar salvo que los críticos elaboren una teoría completa de la democracia constitucional.

Existe otro ejemplo de que para Verdugo resulta evidente que las reglas de súper mayoría deben existir, y que el único problema a discutir es cuándo se deben materializar. En efecto, en otra parte de su artículo, sostiene que: “[...] la pregunta del debate no debe ser si se justifican las leyes org. const., sino ¿en qué materias específicas es conveniente que el proceso legislativo se rigidice? Y esto sólo puede contestarse analizando casuísticamente los tipos de materia a regular" 36 .

Esta cita confirma el sesgo súper-mayoritario de su tesis principal. Él zanja la discusión sobre la legitimidad de las "loc.s" dándola por empatada en el "nivel general" 37 . Lo único que cabría discutir es la extensión de la institución.

En definitiva, un problema esencial de la tesis de Verdugo es que niega el núcleo básico de un sistema de adopción de legislación democrática, como es la regla de mayoría. Quizás sea posible aceptar que la democracia debe complementar regímenes de decisión mayoritarios con otras instituciones contramayoritarias. Las reglas de súper-mayorías para la reforma constitucional o

\footnotetext{
${ }^{35}$ Sunstein, Cass, Legal Reasoning and Political Conflict (Oxford, Oxford University Press, 1996), cap. $2^{\circ}$.

${ }^{36}$ Verdugo, S, cit. (n. 1), p. 407.

${ }^{37}$ Ibíd., pp. 407-08.
} 
el Tribunal Constitucional son dos ilustres ejemplos de tales mecanismos. Pero no es posible aceptar la tesis de que existe un empate de razones a favor y en contra de la regla de mayoría y de la regla de súper mayorías, y que sólo nos queda discutir los casos concretos en que aplicaremos una u otra. Menos razonable aún resulta poner la carga argumentativa sobre los defensores de la regla de mayoría y no de quienes abogan por las súper-mayorías. No es posible aceptar que se altere la carga de la argumentación, cuando se trata de discutir la regla de mayoría como un rasgo básico de un régimen democrático.

\section{Derecho comparado.}

Para justificar que las súper mayorías no se oponen a la democracia, Sergio Verdugo recurre en varios puntos de su exposición al derecho comparado. De un lado, él sostiene que "la existencia de quórums legislativos calificados es frecuente en otros sistemas políticos (como en Austria, Portugal, Bélgica, India, EE.UU., etc.)"38. Dado que todos estos países son normalmente considerados democráticos, Verdugo afirma que el argumento de los críticos sobre el carácter antidemocrático de las "loc.s" sería poco serio ${ }^{39}$. Del otro, para ilustrar "el equilibrio de argumentos en el plano de las justificaciones generales" cita la decisión de la Comisión Europea para la Democracia Mediante el Derecho ("Comisión de Venecia") que criticó la amplitud y el número de materias entregadas por la nueva Constitución de Hungría a la regulación de las súper-mayorías ${ }^{40}$. Del hecho de que las súper-mayorías no hayan sido lisa y llanamente censuradas o denunciadas por esta Comisión sino que aceptadas como una excepción, concluye que estas son una técnica legítima y compatible con la democracia.

En ambos casos, Verdugo abusa de las referencias al Derecho comparado ${ }^{41}$.

En primer lugar, habría que hacer una prevención sobre el valor substantivo de las observaciones de la "Comisión de Venecia". Ésta no es un órgano académico ni directamente político, sino que diplomático; es decir, es un órgano consultivo que, careciendo de legitimidad democrática propia, aspira a establecer estándares de gobernanza razonablemente homogéneos dentro de una región heterogénea persuadiendo a los gobiernos de seguir determinados cursos de acción. En cuanto tal, tiene incluso menos "leverage", menos dominio de la situación bajo su escrutinio, que un órgano jurisdiccional. Por esto, esperar que hubiese llamado al gobierno de Hungría a abolir las leyes

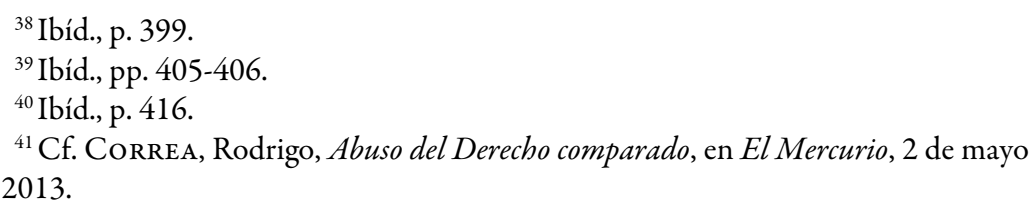


súper-mayoritarias por su incompatibilidad con la teoría democrática o que hubiese emitido una fuerte condena ante su persistencia en la materia es, o bien una expectativa muy ingenua, o bien una estrategia retórica bastante sagaz por parte de Verdugo.

Incluso tomando en cuenta estas limitaciones, se puede apreciar que el documento final de la "Comisión de Venecia" dista considerablemente de la conclusión sacada por Verdugo. Dicho informe, de manera general, está lejos de concluir simplemente que debe discutirse la pertinencia de las súpermayorías en cada caso. Por el contrario, sugiere de manera categórica que son un peligro democrático: "[l]a Comisión de Venecia considera que los parlamentos deben poder actuar flexiblemente para adaptarse a las nuevas condiciones estructurales y hacer frente a los nuevos desafíos dentro de la sociedad [...]. Mientras más asuntos son transferidos fuera del poder de la mayoría simple, menos importancia tendrán las futuras elecciones [y más las posibilidades de congelar el sistema jurídico. Con las súper-mayorías regulando no sólo] principios fundamentales sino también reglas muy específicas y detalladas [...] el principio democrático en sí mismo está en riesgo" ${ }^{\prime 2}$.

Los peligros que la Comisión tiene en mente que podrían afectar a Hungría podrían perfectamente ser sustentados en la experiencia de las "loc.s" en la Constitución chilena. Finaliza su informe considerando que "la necesidad de ciertos quórums podría estar completamente justificada en casos especiales como el núcleo de los derechos fundamentales, las garantías judiciales o las reglas de procedimiento del parlamento" ${ }^{43}$. Ahora bien, de este último no puede seguirse simplemente que las súper-mayorías están legitimadas cuando están justificadas en su contexto específico. Esta afirmación se encuentra en el contexto de una opinión en que las súper-mayorías son consideradas en principio antidemocráticas y peligrosas y que sólo puede ser considerado legítimo su uso cuando concurren tres circunstancias: $i$ ) que se trate de principios fundamentales y no reglas detalladas; $i i$ ) cuando estos principios son muy importantes como los ejemplos citados, no siendo por tanto permisible su uso en asuntos no fundamentales, lo que no debe ser confundido con una mera cuestión cuantitativa; $\mathrm{y}$, finalmente, iii) los casos de súper-mayoría deben estar justificados sustancialmente ${ }^{44}$. Puede concluirse, con la "Comisión de

${ }^{42}$ European Commission for Democracy through Law (2011), Opinion on the New Constitution of Hungary, 2011, pp. 6-7.

${ }^{43}$ Ibíd., p. 7.

${ }^{44}$ Ahora bien, estas últimas observaciones deben ser en sí mismas comprendidas con beneficio de inventario, debido al carácter diplomático que ya hemos anotado. Por esto, es importante llamar la atención respecto del margen de apreciación con que los miembros del Consejo de Europa pueden regular sus propios asuntos internos. Este principio ha sido proclamado especialmente por la Corte Europea de Derechos Huma- 
Venecia", que las súper-mayorías están lejos de encontrarse justificadas, sino que sólo pueden ser toleradas en ciertos casos.

En segundo lugar, la similitud entre las regulaciones extranjeras citadas por Verdugo y las "loc.s" chilenas es bastante menos relevante de lo que el autor pretende. Una breve revisión basta para ilustrar lo anterior. Para comenzar, salvo Estados Unidos y Dinamarca, los otros países citados no establecen quórums supra-mayoritarios distintos al quórum de reforma constitucional. Es decir, los ejemplos de Austria (artículo 44), Uruguay (artículo 331), Costa Rica (at. 195) y Bélgica (artículo 195) son en realidad casos de leyes que se aprueban con quórum de reforma constitucional. Por lo tanto, no existe analogía con el caso chileno. Por otra parte, varias de las reglas de la súper-mayoría citadas se refieren a tratados internacionales (Estados Unidos) o a la transferencia de competencia a organismos internacionales (Dinamarca) ${ }^{45}$. Estos casos nuevamente son distintos al caso chileno en donde los tratados se aprueban con el quórum que corresponda según la materia y la transferencia de competencias requiere -según el Tribunal Constitucional- reforma constitucional. Adicionalmente, varios de los casos usados por Verdugo están insertos en contextos de federalismo (Austria o Estados Unidos) o de regulación de regiones lingüísticas diversas que constituyen un Estado (Bélgica). En estos casos la explicación de las reglas de súper-mayoría tiene relación con la representación de estados o regiones, de manera que explícitamente se abandona la idea de igualdad individual del voto; serían casos de consocionalismo inspirados en el equilibrio entre subculturas políticas ${ }^{46}$, no de democracia protegida orientada a proteger el programa legislativo de una dictadura. Por ello, estos ejemplos tampoco ilustran en nada el caso chileno.

Es cierto que el derecho comparado puede muchas veces iluminar las discusiones internas. Actualmente el aislamiento en materia de derecho constitucional o de diseño institucional no resulta aconsejable. Pero, como

nos, pero también es seguido por todos los órganos del Consejo a la hora de emitir sus opiniones y decisiones y es expresamente citado por la Comisión en este informe. Ello explicaría la tolerancia que la Comisión muestra por una institución por la que no hace ningún esfuerzo por ocultar su antipatía. Sobre la doctrina del margen de apreciación, véase: Letsas, George, Two Concepts of the Margin of Appreciation, en Oxford Journal of Legal Studies, 26 (Oxford, 2006) 4, pp. 705-732.

${ }^{45}$ La justificación de la regla en Estados Unidos, en particular, es fuertemente cuestionada incluso entre los defensores de las super-mayorías, Véase: RAppaporT, Michael - McGinnis, John, cit (n. 26), pp. 51-60.

${ }^{46}$ Para una (relativamente) reciente formulación por su autor de la teoría del consocionalismo y el diseño de mecanismos constitucionales de distribución de poder dentro de sociedades culturalmente fragmentadas, véase: Lijphart, Arend, Constitutional Design for Divided Societies, en Journal of Democracy, 15 (2004) 2, pp. 96-109. 
hemos visto, en el debate sobre las "loc.s" las referencias al derecho comparado han sido débiles, descontextualizadas e incluso podríamos decir abusivas.

\section{La superpoblación de mecanismos contra-mayoritarios.}

Para concluir esta sección, nos referiremos a la interacción entre las "loc.s" y el resto de los mecanismos constitucionales. En efecto, uno de los principales argumentos que Verdugo utiliza es que quienes critican las "loc.s" "no consideran el resto de instrumentos contra-mayoritarios existentes en el proceso legislativo". Esos arreglos contra-mayoritarios serían: "Entre otros: i) existen dos cámaras legislativas; ii) posibilidad de paralizar un proyecto de ley por no ejercerse la facultad de darles urgencia; iii) el veto presidencial y la posibilidad de insistencia por parte el Congreso sólo cuando se reúne una súper-mayoría; iv) el control constitucional del Tribunal Constitucional en sus diferentes formas; $v$ ) las cuestiones de iniciativa exclusiva (unido al régimen de ideas matrices) que quitan capacidad legislativa a los parlamentarios; vi) las cuestiones reguladas directamente en la constitución; y vii) las leyes con exigencia de quórum súper-mayoritario" ${ }^{37}$.

Según Verdugo, todos estos arreglos se relacionan de manera "dinámica en un proceso político donde participan varios actores interesados, y cada uno sigue fines diversos [contribuyendo] a la existencia de escollos para modificar el statu quo [...] y reduciendo (sin eliminar) las posibilidades de generar reformas políticas profundas" ${ }^{48}$. Las críticas contra las "loc.s", sostiene, han carecido de un "examen de la interrelación de varias instituciones que producen arreglos contra-mayoritarios, y que en algunos casos configuran un “jugador con veto' [...] presente en el proceso legislativo" ${ }^{49}$. En esos términos, sostiene que debe considerarse, en la eventual reforma de la institución de las "loc.s" su efecto en el resto de los arreglos institucionales.

Las diatribas dirigidas por Verdugo a los críticos de las "loc.s", donde señala que "ellos suelen no considerar el resto de los arreglos institucionales relevantes del sistema ni considera (ni pondera) los bienes que la técnica de las leyes org. const. está llamada a servir" son ideológicas, por cuanto le permiten ocultar una de las principales fisuras en su propia argumentación. Señalando que al analizar las "loc.s" se ha ignorado la complejidad de los arreglos políticos, justamente apunta a uno de los factores que ha generado mayor controversia en relación con éstas. Incluso reconociendo que " $[h] a y$ buenas razones para argumentar que en nuestro sistema político tenemos un exceso de 'jugadores con veto' en el proceso legislativo", Verdugo con-

\footnotetext{
${ }^{47}$ Verdugo, S., cit. (n. 1), p. 411.

${ }^{48}$ Ibíd., p. 412.

${ }^{49}$ Ibíd., p. 411.
} 
cluye que ello no debe necesariamente llevarnos a eliminar las "loc.s" sino que a "hacernos pensar en el diseño de un modelo equilibrado que siga con efectividad los fines que queremos perseguir". Sin embargo, el problema que Verdugo oculta retóricamente -y, por ello, ideológicamente- es que el exceso que él mismo reconoce produce un efecto acumulativo que desnaturaliza la función protectora de las minorías que, en abstracto, tienen los arreglos contra-mayoritarios o súper-mayoritarios, con lo que devienen en concreto en una simple traba del proceso democrático.

Primero, desde la perspectiva de su diseño original -que no es una buena perspectiva para buscar la legítima autoridad pero sí para buscar la intención con que ciertas instituciones fueron establecidas- las llamadas instituciones de la democracia protegida no buscaron diferentes finalidades a través de variadas técnicas, sino que es bien sabido que pretendían servir -y han sido exitosas en ello- como un instrumento dentro de un engranaje mayor para ahogar la expresión de la voluntad popular. Las "loc.s", el sistema binominal, los senadores designados, el Tribunal Constitucional, y muchos otros dispositivos, vistos en conjunto, fueron precisamente establecidos para deshabilitar la política de mayorías -y potencialmente redistribuidora- en Chile. Ello queda en evidencia en una cita que parece estar cobrando notoriedad en la que Jaime Guzmán confesaba: "si llegan a gobernar los adversarios, se vean constreñidos a seguir una acción no tan distinta a la que uno mismo anhelaría, porque -valga la metáfora- el margen de alternativas posibles que la cancha imponga de hecho a quienes juegan en ella, sea lo suficientemente reducido para hacer extremadamente difícil lo contrario" ${ }^{\text {" }}$.

No se entiende, entonces, cómo el argumento sistemático al que apela Verdugo podría justificar su posición. ¿En qué medida la acción conjunta entre mecanismos contra-mayoritarios y supra-mayoritarios eximiría al sistema constitucional chileno de la acusación de ser un aparato de protección de intereses y de perpetuación del programa de la dictadura?

Verdugo ofrece un intento de diferenciación funcional entre dos de los más criticados mecanismos de amarre ("loc.s" y binominal), señalando que el sistema electoral binominal tiene como función determinar algunos elementos del sistema de partidos y representación y que es relativamente independiente de la reglas de súper-mayoría. Prueba de ello es que con un sistema electoral proporcional sería aún más difícil aprobar una ley de quórum súper-mayoritario ${ }^{51}$. Este ejemplo es una muestra de que Verdugo no entiende el problema que presenta o quiere decididamente engañar al lector

\footnotetext{
${ }^{50}$ Citado en Correa, Sofía y otros, Historia del siglo XX chileno: balance paradojal (Santiago, Sudamericana, 2001), p. 325.

${ }^{51}$ Verdugo, S., cit. (n. 1), pp. 415.
} 
mediante complicaciones. Por un lado, el efecto acumulativo de las instituciones contra-mayoritarias no se mide de acuerdo a la hipotética dificultad para aprobar una ley, sino de acuerdo a la diferencia entre las preferencias expresadas en el voto de los ciudadanos y las políticas públicas que tienen como resultado el proceso político. El efecto acumulativo se mide, entonces, no como un déficit de gobernabilidad sino como un déficit de identidad entre la voluntad del pueblo y las medidas tomadas por las instituciones del Estado. Tanto en el sistema binominal como en las súper-mayorías, la forma de expresión de la voluntad del pueblo, la regla de decisión por mayoría, es deferida por una regla distinta; en ambos casos, por una regla que empodera a la minoría en el procedimiento político. Por otro lado, y esta es la parte en que Verdugo parece querer tomar el pelo al lector, no se entiende cómo puede ser que el hecho de que el sistema binomial haga más fácil los acuerdos que un sistema proporcional constituya una razón para defender las súpermayorías o el sistema binominal ${ }^{52}$.

Segundo, la idea del efecto acumulativo es, de alguna manera, sensible a que una democracia coexista con algunos arreglos contra-mayoritarios, siempre y cuando estos no hagan imposible ver a tal democracia como tal. Sin embargo, del hecho de que existan instituciones contra-mayoritarias justificables no se sigue que toda institución contra-mayoritaria esté justificada. Por ejemplo, uno puede defender el sistema electoral proporcional porque busca proteger a las minorías, pero eso no obliga a defender un Tribunal Constitucional con poderes de anulación de legislación. Tampoco el bicameralismo -que también es un dispositivo contra-mayoritario- por sí mismo podría llevar a defender las súper-mayorías. El argumento debe llevarnos justamente en la dirección opuesta. Una buena razón para suprimir las "loc.s" es que ya tenemos varios otros mecanismos de protección de minorías y de "enfriamiento" del proceso legislativo menos lesivos del principio de igualdad política.

Siguiendo con el planteamiento de Verdugo en cuanto a juzgar las instituciones individualmente consideradas a la luz del contexto institucional dinámico en el cual están insertas, se puede sostener perfectamente que, por ejemplo, el "filibuster" en Estados Unidos es un mecanismo que no elimina

${ }^{52} \mathrm{~A}$ esto habría que sumarle que el binominal persigue finalidades extra-legislativas, más bien cercanas al disciplinamiento del sistema de partidos y por lo tanto de los proyectos políticos disponibles para la ciudadanía. Por lo tanto, las "loc.s" y el binominal forman parte de un continuo de estrategias destinadas a la desaparición de proyectos políticos redistributivos de la que forman parte también, y en su extremo más inhumano, la prohibición de partidos de izquierda vigente durante toda la dictadura y el secuestro, tortura, exilio, asesinato y desaparición de parte importante de la militancia y la dirigencia de la izquierda chilena. 
el carácter democrático de la sociedad estadounidense, pero que incrementa considerablemente la dificultad de llevar a cabo los programas legislativos aprobados electoralmente por las mayorías. Ahora bien, incluso allí los extremos a que el "filibuster" ha sido llevado por la oposición republicana a la Presidencia de Obama han generado crítica por parte de los analistas políticos, e incluso se ha empezado a discutir su reforma. Ciertamente, no por esto Estados Unidos debiera ser sacado de los índices democráticos; pero si se le pregunta a un votante norteamericano, lo más probable es que diga -empleando las palabras según su significado cotidiano, no técnico- que la minoría republicana en el Senado ha vulnerado la democracia al forzar el uso de la súper-mayoría en lugar de la regla de mayoría como procedimiento general ${ }^{53}$.

Tercero, la principal razón por la cual el sistema binomial con las "loc.s" son el principal objetivo de los críticos de la "democracia de acuerdos" es que ellas son categorialmente distintos a, por ejemplo, el control constitucional del Tribunal Constitucional o la intervención mediante vetos y urgencias por parte del presidente de la República. En estos dos últimos casos, el mecanismo es en estricto sentido contra-mayoritario dado que la mayoría de los parlamentarios ha decidido democráticamente y es la voluntad de otro órgano del Estado la que se contrapone a dicha voluntad democrática. El efecto político que produce este choque entre la voluntad democrática del Congreso Nacional y otro órgano constitucional no puede ser desestimado; efecto que, a su vez, constriñe el propio uso de dicho mecanismo. La diferencia con el sistema binominal y las "loc.s" estriba en que estos no son mecanismos contra-mayoritarios en este sentido, porque ellos impiden a la mayoría formularse en cuento tal. Ellos constituyen una especie de censura legislativa, que produce que los ciudadanos no puedan identificar claramente quién está decidiendo -y por tanto quién debe asumir responsabilidades por dicha decisión-, si es la mayoría o la minoría parlamentaria. En cambio, la identidad de quién decide es evidente cuando quien decide contramayoritariamente es el presidente o el Tribunal Constitucional; esto es, un órgano externo al Congreso. De cara a esta diferencia, si ha quedado claro que se debe evitar una superpoblación de esta clase de mecanismos; que no porque un mecanismo esté justificado todos ellos lo estarán; y que existen mecanismos contra-mayoritarios preferibles a otros, entonces resulta que el argumento sistemático avanzado por Verdugo habla a favor de las supresión de las "loc.s" de la Constitución antes de que de su mantención.

${ }^{53}$ Marziani, Mimi - Backer, Jonathan - Kasdan, Diana, Curving Filibuster (New York, Brennan Centre of Justice, 2012); y Liss, Susan - Murray, Mimi - MarZIANI, Digby, Filibuster Abuse (New York, Brennan Centre of Justice, 2012). 


\section{LA JUSTIFICACIÓN ESPECÍFICA DE LAS LEYES ORGÁNICAS CONSTITUCIONALES}

\section{La justificación especifica.}

En la sección final de su artículo, Verdugo esgrime el argumento que constituye el núcleo de su posición. Él sugiere que la discusión sobre las "loc.s" sólo tiene sentido en el nivel específico de la regulación de cada materia. Una discusión puramente general, argumenta, es inevitablemente infértil.

Sin perjuicio de que analizaremos sus justificaciones específicas en detalle a continuación, acá se hace necesario señalar una consideración general respecto a ellas. Verdugo es incapaz de trazar una línea entre las materias que deben ser objeto de decisiones súper-mayoritarias y, por lo tanto, deben estar situadas en el nivel propiamente constitucional, de aquellas que sólo merecen un tratamiento de "loc.". Pareciera ser que su argumento es que tratar todas las materias como constitucionales implicaría una sobrecarga del texto constitucional. Entonces, según esta interpretación de su postura, es necesario alcanzar un punto medio a través de las "loc.s". Sin embargo, no da pautas de qué materias corresponden a cada categoría: súper-mayoría constitucional; súper-mayoría legal o moderada; mayoría simple. Esto lo lleva inevitablemente a una pendiente resbaladiza.

Verdugo señala que las "loc.s" son razonables respecto de las reglas que regulan los principales órganos de control, el sistema electoral, las autonomías de órganos constitucionales, entre otras. Sugiere que acá puede haber graves desacuerdos políticos entre los actores, y una regla de mayoría simple acarrea graves riesgos de opresión, corrupción y acumulación excesiva de poder. Si esto es cierto, ¿no es posible sostener lo mismo respecto de todos los derechos fundamentales? ¿Respecto de qué materias no es posible sostener un argumento similar, especialmente cuando se argumenta a la luz de las premisas de la "public choice"? A pesar de su apariencia de moderación, el argumento aplicado consistentemente nos llevaría a que casi todas las materias políticamente significativas sean (o sigan siendo) propias de "loc." En consecuencia, con esta propuesta el daño al principio de igualdad política se perpetúa, tal como se han tratado de perpetuar las instituciones de la dictadura.

Ahora bien, entrando directamente en el análisis de las justificaciones especiales ofrecidas por Verdugo, es necesario reconocer que existe una distancia considerable entre la oferta del autor, consistente en "fundamentar por qué dicha regla [de súper-mayoría] es conveniente en el caso particular de una materia específica" 54 , y lo efectivamente explicado en cada caso particular. Uno hubiese esperado, por ejemplo, una comparación gramatical,

${ }^{54}$ Verdugo, S., cit. (n. 1), p. 416. 
lógica y dogmática entre el texto constitucional y los contenidos efectivos de las "loc.s"; o bien, un análisis propiamente institucional y empírico de la interacción que ha existido entre presiones reformistas por parte del constituyente derivado y el legislador súper-mayoritario y los órganos por ellos regulados. Las justificaciones especiales de Verdugo, sin embargo, son demasiado genéricas; parecieran girar en torno o bien a la importancia de la materia regulada por súper-mayorías, o bien en torno a la existencia de incentivos que tentarían al constituyente derivado y al legislador de afectar las atribuciones del órgano regulado. Y, ¿respecto de qué asunto constitucional no podría ser dicho otro tanto?

La discusión de los diversos argumentos entregados por Verdugo nos permitirá, según creemos, dar sustento renovado a la creencia central que anima a quienes han abogado desde 1980 por el retorno a un constitucionalismo democrático, alejado del proyecto autoritario de democracia protegida; esto es, que los supuestos vicios de la democracia sólo se pueden superar con más democracia. En específico, las aparentes debilidades del diseño constitucional son simplemente las debilidades de todo gobierno humano; y si bien la adición de 'frenos y contrapesos' y 'jugadores con veto' pueden reducir las oportunidades para el despliegue del vicio y el comportamiento faccioso, ellos también pueden reducir las oportunidades para la acción colectiva legítima, al paso que pueden -como ocurre con las "loc.s"- desnaturalizar a la democracia misma mediante el desconocimiento de su postulado fundamental, la igualdad política.

A continuación, discutiremos los ejemplos concretos de justificaciones de súper-mayorías que propone Verdugo; esto es, aquellas que afectan a los órganos de control del poder político, el sistema electoral, los órganos constitucionales autónomos, y el proceso legislativo, respectivamente.

\section{2. Órganos de control del poder politico.}

Verdugo nos dice que los órganos de control político "están en tensión con las facultades del presidente y del Congreso, y que sin embargo tienen poca influencia en el diseño regulatorio de sus estructuras" 55 . Ahora bien, frente a esta afirmación cabe preguntarse lo siguiente: es que eso no es una característica propia del constitucionalismo? Si no fuera así, ¿qué sentido habría en distinguir entre órganos políticos y órganos de control?

Desde luego, la no participación de los órganos de control en el diseño institucional -cuya elaboración atribuyen tanto la teoría como la práctica constitucional a los órganos políticos- ofrece oportunidades para conductas perversas, donde, por ejemplo, los propios diseñadores escapen del control;

${ }^{55}$ Ibíd., p. 418. 
piénsese, sin ir más lejos, en todo el entramado de disposiciones transitorias incorporado por la Junta Militar, que constituían en su conjunto un gran mecanismo no sólo de "amarre" sino también de "escape". En la actualidad, el ya mencionado caso de Hungría (véase más arriba II,4) ofrece un ejemplo similar de "escape" 56 . Ahora bien, y aquí está el punto que las prevenciones de Verdugo obvian, ambos casos se han dado en contextos de autoritarismos - militar en un caso, populista en el segundo- caracterizados por la supresión del debate público.

En contextos de deliberación democrática libre, sin embargo, toda iniciativa que ataque directamente a los órganos de control en su capacidad de supervigilar a los órganos políticos representa un costo político muy grande. Piénsese en el "court-packing plan" formulado por el presidente Franklin D. Roosevelt para, frente a la actitud opositora de la Corte Suprema hacia el "New Deal", sumar a dicho órgano jueces alineados con sus políticas económicas que sobrepasaran a los jueces conservadores. La opinión pública percibió la iniciativa de Roosevelt como un ataque a la propia Constitución, y el proyecto de ley fue desechado por el Congreso, con la oposición incluso de parlamentarios demócratas ${ }^{57}$. Así, el intento de Roosevelt de atacar a un órgano de control le significó un costo político muy grande ${ }^{58}$. La moraleja de esta historia es que, en un contexto deliberativo, los órganos de control no necesitan de más protecciones que las que les entrega el proceso legislativo ordinario.

Esta historia sirve también para atender la siguiente preocupación de Verdugo; esto es, que "tanto el Ejecutivo como el Legislativo tienen fuertes incentivos para amenazar las atribuciones de estos órganos" 59 , específicamente la manera en que dichos órganos implementan sus atribuciones propias. Claro, Roosevelt pudo haber querido que la Corte Suprema aceptara su interpretación de la "commerce clause", o nuestra Presidencia podría querer convocar a plebiscito en una materia no contemplada por la Constitución, por ejemplo solicitando a la ciudadanía pronunciarse afirmativa o negativamente sobre la realización de una asamblea constituyente. En estos casos

\footnotetext{
${ }^{56}$ En este sentido, véase: Palonen, Emilia, Transition to Crisis in Hungary: Whistle-Blowing on the Naked Emperor, en Politics \& Policy, 40 (2012) 5, pp. 930-957.

${ }^{57} \mathrm{Si}$ bien en el intertanto la sentencia "West Coast Hotel v. Parrish", 300 U.S. 379 (1937), marcó un cambio en la orientación jurisprudencial de la Corte -el así llamado "switch in time that saved nine"- lo cierto es que dicha sentencia ya estaba resuelta antes del anuncio por parte del presidente Roosevelt de su proyecto de ley y, lógicamente, de su fracaso.

${ }^{58}$ Costo que, adicionalmente, fue innecesario. Para un análisis en detalle del "courtpacking plan" y del "switch in time" de la Corte, véase: Ackerman, Bruce, We the People, II: Transformations (Cambridge, Harvard University Press, 1998), pp. 281 ss. ${ }^{59}$ Verdugo, S., cit. (n. 1), p. 418.
} 
específicamente políticos de vulneración del control, la discusión sobre diseño constitucional resulta bastante secundaria; se trata de actos de instrumentalismo jurídico -real el primero, hipotético el segundo- que hacen su aparición en momentos de crisis y que no pueden ser previstos en la medida en que inevitablemente hacen uso de intersticios interpretativos para intentar hacer frente a crisis, reales o pretendidas, del orden constitucional.

Ahora, en casos y situaciones de mayor normalidad, donde no está en juego la preservación del orden constitucional sino que la simple resolución de políticas públicas, es muy poco plausible pensar que los órganos políticos intentarán destruir a los órganos de control. Piénsese en la polémica que siguió a la sentencia del Tribunal Constitucional sobre la píldora del día después. Ciertamente, hubo llamados desde la opinión pública y desde la clase política a restringir la jurisdicción de la Corte; pero nada de ello prosperó, ni siquiera materializándose en iniciativas serias por llevar a cabo dicha restricción. Ciertamente, el Tribunal Constitucional terminó plegándose a la interpretación favorable a la constitucionalidad de la píldora ${ }^{60}$; pero, ¿hay algo de malo en que, tal como ocurrió respecto del "New Deal", una interacción sostenida entre actores sociales y políticos lleve a un tribunal a cambiar su interpretación sobre la constitucionalidad de una medida o política pública ${ }^{61}$

Verdugo, que no acude a casos de estudio, podría eventualmente haberse solazado con el caso de Salvador Allende, quien durante su gobierno desconoció varias órdenes judiciales de desalojo de inmuebles ocupados por campesinos y trabajadores. En dichos casos, el presidente Allende argumentó que la Ley de seguridad interior del Estado le autorizaba a ponderar la ejecutabilidad de las sentencias judiciales a la luz de su impacto en la paz y el orden social. Como sabemos, dicho argumento llevó a que el texto constitucional actualmente vigente le atribuyera directamente al Poder Judicial la facultad de imperio, a fin de permitirle el hacer ejecutar por sí mismo lo por él resuelto. Sin embargo, este caso nos muestra que la súper-mayoría no es idónea para enfrentar los peligros previstos por Verdugo. A Allende le bastó con elaborar una síntesis interpretativa novedosa para darle sustento jurídico a su actuar, una posibilidad que las súper-mayorías no pueden conjurar.

Más preocupante sería, desde luego, que similares intentos de instrumentalismo fueran empleados para evadir el control ya no de constitucionalidad sino de responsabilidad administrativa que le cabe a quienes desempeñan funciones públicas. Este es el ejemplo que Verdugo tiene en mente al señalar que "un funcionario público no quiere que la Contraloría General de

${ }^{60}$ Sentencia de 14 de enero de 2010, recaída en la causa rol No $1588-2010$.

${ }^{61}$ Para una elaboración teórica de esta interacción véase: PosT, Robert - SIEGEL, Reva, Constitucionalismo democrático. Por una reconciliación entre Constitución y pueblo (Buenos Aires, Editorial Siglo XXI, 2013). 
la República le abra un sumario"62. Afortunadamente, no se divisa cómo podría un funcionario público alterar las atribuciones de la Contraloría. Desafortunadamente para Verdugo, eso le resta justificabilidad especial a la súper-mayoría en este caso.

Por cierto, Verdugo observa que el texto constitucional vigente emplea variados mecanismos para generar "accountability" por parte de los órganos políticos y autonomía para los órganos de control, entre los cuales se encuentran la incorporación de algunos de estos órganos en el propio texto constitucional y la prohibición de delegación legislativa en materia de su regulación. Aquí vuelve a surgir la pregunta que ya nos hemos hecho anteriormente: ¿no es suficiente con estas precauciones? Ellas, por cierto, preceden a la Constitución actualmente vigente. El Poder Judicial es el órgano que recibió su regulación constitucional más temprana en 1823; la Contraloría fue "constitucionalizada" en 1943 mediante la Ley o 7.727, tan sólo 16 años después de ser creada como tal por el Decreto con Fuerza de Ley No 400-bis; y el Tribunal Constitucional fue incorporado a nuestra Carta Magna por la Ley No 17.284, la misma que lo creó el 23 de enero de 1970. Las atribuciones contraloras de todos estos órganos siempre han estado fijadas en lo medular por el texto constitucional, y en nuestra opinión no se divisa algún momento - ni antes de 1973, ni después de 1990- en que dichos órganos hayan estado amenazados por el legislador ordinario.

Otra cosa distinta es la participación consultiva del órgano de control en el proceso legislativo, algo que ocurre sólo en el caso de la Corte Suprema. Esta es una medida que constituye una intervención menos lesiva en el carácter democrático del proceso legislativo, pues permite aprovechar la eventual experticia del órgano sin entregarle un "veto" en el sentido politológico de la expresión. Sin duda es positivo que el legislador recurra a dicha experticia; sin embargo, precisamente por lo recién apuntado, es necesario que dicha contribución se dé en los términos en los que se da actualmente la participación de la Corte Suprema, esto es como un insumo más en la discusión. Mal que mal, en el caso de la legislación, lo que le pedimos a la Corte Suprema es que nos dé su opinión política; su opinión sobre cómo debiera estar estructurada una institución pública, el Poder Judicial, de la cual ocurre que la Corte es parte integrante. La Corte Suprema, por ejemplo, opinaba que la Ley No 20.609, de Medidas contra la discriminación, era innecesaria por ser redundante con disposiciones legales ya existentes. Pero la sociedad -y numerosos juristas- consideró que aquello que para la Corte era suficiente, era insuficiente. ¿Hubiese acaso sido mejor que la Corte hubiese podido detener la aprobación de dicho proyecto de ley?

${ }^{62}$ Verdugo, S, cit. (n. 1), p. 418. 
Siguiendo con la discusión del Poder Judicial, Verdugo aporta un interesante ejemplo al mencionar el peligro del populismo penal, el cual ocurre "cuando la población le reprocha responsabilidad [al Poder Ejecutivo] por el aumento de los índices de criminalidad y denuncia" ${ }^{63}$. Ciertamente, y a diferencia de los beneficiarios de las protecciones estructurales creadas por la democracia protegida en beneficio de grupos de poder, este sí es un caso donde hay minorías vulnerables cuyos derechos están en juego y llevan las de perder. Sin embargo, ¿cómo podría el requisito de súper-mayoría ayudar a los grupos sociales marginales, tanto aquellos meramente sospechosos de estar involucrados en conductas delictuales como aquellos que efectivamente han incurrido en dichas conductas? ¿Es que acaso Verdugo supone ahora, olvidando las enseñanzas de la "public choice" que le son tan caras, que la minoría parlamentaria se va a compadecer de estos grupos desaventajados por mero altruismo?

Lo cierto es que no hay ninguna forma de que la súper-mayoría ayude estructuralmente a proteger los derechos de los sospechosos y los delincuentes. La manera específica de hacerlo es entregándole mayor autonomía institucional a la defensoría penal pública y fortaleciendo a los tribunales orales en lo penal y de garantía. Claro, si dichos cambios son realizados a través de la legislación, la racionalidad estratégica indica que uno querrá protegerlos del cambio futuro mediante mecanismos de súper-mayoría; pero eso puede ser dicho respecto de cualquier contenido legislativo. Para eso existe la Constitución, por lo demás; introduciendo allí los cambios de diseño centrales en esta u otras materias, las súper-mayorías pasan a ser irrelevantes desde el punto de vista del diseño, amén de ser lesivas de la igualdad política según se ha dicho.

El ejemplo del populismo penal nos hace ver que, en aquellos casos en los que están en juego las funciones de órganos de control, no es evidente que la minoría parlamentaria estará del lado del órgano de control. Gobierno y oposición podrían estar de acuerdo, por ejemplo, en darle a todos los parlamentarios una amnistía por algún delito tributario en el que unos y otros hubiesen incurrido. Ese es el sentido de la cita a Schmitt que llamara la atención de Verdugo: "la peligrosa mayoría más fuerte es, evidentemente, mucho más peligrosa que la peligrosa mayoría simple" ${ }^{64}$. ¿Significa esto que ante esa súper-mayoría está todo perdido? La respuesta es que eso depende del contexto. En un contexto de libertades políticas y de deliberación, la presión de otros actores sociales y políticos debiera ser capaz de detener dicha amnistía. En un contexto de pasividad cívica o, derechamente, de autoritarismo,

${ }^{63}$ Ibíd., p. 420.

${ }^{64}$ Schmitt, Carl, Legalidad y legitimidad, en Orestes, Héctor (editor), Carl Schmitt, teólogo de la Política (Ciudad de México, Fondo de Cultura Económica, 2001), p. 292. 
ni el requisito de súper-mayoría podría detenerlo. Entre ambos extremos, ciertamente, hay múltiples puntos de equilibrio, y lo único que nos queda a nosotros mismos como ciudadanos es involucrarnos en defender aquello que ninguna súper-mayoría puede garantizarnos: el carácter democrático y republicano de nuestra Constitución.

\section{Sistema electoral y Tribunal Calificador de Elecciones}

¿Qué justificación especial se nos ofrece en el caso de las "loc.s" relacionadas con el proceso electoral? Verdugo afirma que el objetivo de estas normas "es producir un sistema electoral que entregue ciertas garantías democráticas a los actores políticos relevantes" 65 . Ahora bien, es imposible dejar de observar que dicha afirmación adquiere un carácter bastante paradojal cuando es puesta en el contexto histórico-político que le corresponde; mal que mal, es precisamente el sistema electoral uno de los terrenos donde la Junta Militar jugó más sucio al momento de legislar, tanto al momento de diseñar los distritos y circunscripciones en función de los resultados del plebiscito de $1988^{66}$ como al momento de escoger el sistema electoral en función del mismo objetivo ${ }^{67}$.

Obviemos por el momento este hecho, y pensemos en el diseño institucional en abstracto. $\mathrm{Al}$ respecto, hay que señalar que si lo que nos preocupa es la imparcialidad del diseño electoral, hay mecanismos más adecuados que la súper-mayoría para alcanzarla o potenciarla. Una de ellas consiste en someter todo cambio en el diseño electoral al estudio de un organismo técnico, idealmente sustraído del proceso político. Algo así ocurre, por ejemplo, en el requerimiento establecido en Estados Unidos en la Voting Rights Act de 1965, que exige a ciertos estados someter a aprobación previa del Depar-

${ }^{65}$ Verdugo, S., cit. (n. 1), p. 422.

${ }^{66}$ Véase la presentación hecha en la causa rol No 67 del Tribunal Constitucional por Carlos Geywitz, Francisco Cumplido, Humberto Nogueira, Jorge Precht, Germán Urzúa y Mario Verdugo en la que se cuestiona, en nombre de la igualdad política, la desigual cantidad de electores contenidos por diversos territorios electorales. El Tribunal desechó dicha objeción en su sentencia de 12 de mayo de 1989 arguyendo que el "reparo de constitucionalidad en referencia, carece de todo fundamento, ya que el constituyente entregó al legislador de la ley orgánica constitucional respectiva la determinación de los distritos electorales". Cabe señalar que, si a uno le interesa no sólo la racionalidad abstracta del diseño institucional sino su capacidad de modelar efectivamente la conducta social, es este tipo de usos de las "loc.s" -es decir, la manera en que efectivamente han sido usadas- los que debieran servir como parámetro para su evaluación, no argumentos hipotéticos.

${ }^{67}$ Sobre el proceso a través del cual efectivamente se diseñó el sistema electoral, véase: Pastor, Daniel, Origins of the Chilean Binominal Election System, en Revista de Ciencia Politica, 24 (Santiago, 2004), pp. 38-57. 
tamento de Justicia cualquier cambio que hagan a sus leyes relacionadas con el derecho a voto ${ }^{68}$. En nuestro caso, este rol lo podría desempeñar un Servicio Electoral institucionalmente reformado y reforzado. Esta solución, por cierto, no requiere del recurso a las súper-mayorías. Incorporados en la Constitución los objetivos y las respectivas disposiciones orgánicas y procedimentales medulares, la finalidad planteada por Verdugo se cumpliría de mejor manera que recurriendo a una ley súper-mayoritaria. También podría ser el Tribunal Constitucional el que se encargara de verificar la imparcialidad de las reglas electorales. Desde luego, tendría que ser un Tribunal que se tomara en serio su función de custodio de la igualdad y la imparcialidad en el proceso electoral ${ }^{69}$.

El punto es que la mera suma de mayorías -esto es, la súper-mayoría- no está estructuralmente alineada con el propósito deseado por Verdugo. La súper-mayoría no garantiza de ninguna manera mayor imparcialidad en el diseño electoral. El propio autor nos ofrece un ejemplo precisamente de ello: el caso "descolgados". "En este caso, la exigencia súper-mayoritaria de ley org. const. fue insuficiente, atendido que los independientes en el Congreso no alcanzan una capacidad de veto suficiente dentro del proceso legislativo" ${ }^{\prime 0}$, observa Verdugo. ¿Significa eso que a fin de lograr la imparcialidad del proceso electoral hemos de saltar de la súper-mayoría al requisito de la unanimidad? Ya hemos desechado por razones de principio dicha alternativa (más arriba II,1). Baste simplemente reiterar que en este tipo de casos, donde está en juego no el interés de la mayoría parlamentaria sino prácticamente de la totalidad de los parlamentarios, el requisito de súper-mayoría se revela como inconducente. Para todo aquello respecto de la cual la mayoría simple no constituye una garantía, está el Estado de Derecho y sus instituciones, más específicamente la revisión de constitucionalidad. Si esta no funciona, menos aún funcionará la súper-mayoría.

\section{4. Órganos constitucionales autónomos.}

El caso de los órganos constitucionales autónomos se asemeja al del ejemplo hipotético ofrecido en la sección anterior. ¿Qué necesidad hay de que, habiendo sido resuelto el diseño orgánico y procedimental fundamental de un órgano determinado, haya una "loc." que regule su detalle organizacional?

${ }^{68}$ Véase: Epstein, David y otros (editores), The future of the Voting Rights Act (New York, Russel Sage Foundation, 2006).

${ }^{69}$ Esto es, tendría que ser un tribunal más fiel a la jurisprudencia de su sentencia Rol № 33, en la que ordenó la realización del plebiscito de 1988 con registros electorales, que a la de su sentencia Rol № 67, donde -según hemos visto en la n. 67- desechó las objeciones contra el diseño electoral de la dictadura basadas en la igualdad política.

${ }^{70}$ Verdugo, S., cit. (n. 1), p. 423. 
Hablando específicamente del Ministerio Público, la discusión no puede obviar el preguntarse por qué habría de estar esta institución mencionada siquiera en la Constitución. La pregunta va en la línea del peligro del populismo penal apuntada por Verdugo anteriormente: es razonable impedir constitucionalmente que el Ejecutivo se aboque la persecución penal. El establecimiento constitucional del Ministerio Público y la entrega a éste en monopolio de la dirección de la investigación de los hechos constitutivos de delito y del ejercicio de la acción penal pública, entre sus atribuciones más significativas, es una garantía de imparcialidad en la persecución penal y de independencia frente al Ejecutivo. Si esto es así, entonces ¿qué añade a esto la existencia de una "loc." fortalecida por la súper-mayoría? La regulación constitucional es clara, y consigue en el plano general y abstracto el objetivo perseguido $^{71}$; y si así no fuera, como Verdugo insinúa que ocurre con el Banco Central, lo que hay que hacer es precisar allí qué criterios constitucionales debe satisfacer la legislación y qué límites no puede transgredir, o bien encontrar dichas respuestas en la jurisprudencia constitucional. ¿Qué nos puede llevar a creer que encontraremos dichas respuestas en la unión de la mayoría y la minoría parlamentarias?

Un caso especial en relación con lo anterior lo ofrece la afirmación de Verdugo de que en el caso del Banco Central "el texto constitucional es muy breve" ${ }^{\text {"72 }}$.Esta afirmación resulta confusa, pues desordena los supuestos lógicos del tipo de discusión que Verdugo dice querer tener. ¿Es esta una discusión sobre la Constitución efectivamente existente, y la justificabilidad de la súpermayoría y de las "loc.s" que efectivamente tenemos? Si es así, entonces la conclusión es que la Constitución y las "loc.s" que tenemos son un esfuerzo de la mano muerta de Pinochet por gobernar el presente, y que a los ojos de cualquier persona moralmente comprometida con el autogobierno son radicalmente ilegítimas. Ahora, si ésta es, como suponemos que Verdugo lo desea, una discusión sobre la justificabilidad hipotética de las "loc.s" tenidas por "buenas" -democráticas, eficientes, racionales, justas-, entonces un supuesto (totalmente hipotético) de la discusión es que contamos con una Constitución "buena"; lo que involucra, entre otras características, que esté "bien" redactada, es decir, que tenga la extensión o desarrollo adecuado. En

${ }^{71} \mathrm{El}$ “caso bombas" y la extraña relación desarrollada entre el ahora ex fiscal Alejandro Peña y el entonces ministro del Interior Rodrigo Hinzpeter sugiere que, en casos concretos, pueden haber amenazas a la independencia y profesionalismo del Ministerio Público. Sin embargo, este mismo caso nos evidencia que dichos peligros, de carácter concreto, no pueden ser conjurados mediante requerimientos de súper-mayoría sino que deben ser combatidos mediante las herramientas de la opinión pública y el Derecho administrativo

${ }^{72}$ Verdugo, S., cit. (n. 1), p. 426. 
tal Constitución, el capítulo sobre el Banco Central no sería "muy breve", y la "loc." no estaría en la necesidad de desarrollar sus contenidos debido a que el constituyente no cumplió cabalmente su tarea. O bien, el capítulo sobre el Banco Central sería breve porque así lo quiso el constituyente, y entonces lo natural sería que sus contenidos fueran desarrollados por la ley simple.

Respecto del Banco Central, hay que señalar que aquel no asegurará "la racionalidad económica" ${ }^{33}$ porque su ley haya sido aprobada por mayoría simple o por súper-mayoría. Esa afirmación es de una ingenuidad supina. De partida, es bueno tomar en cuenta algo que quizás el autor de la cita original no sabe pero que, suponemos, Verdugo sí tiene presente: no existe "la racionalidad económica" así, en abstracto, desprovista de filiaciones intelectuales o ideológicas y de consecuencias político-sectoriales. Una afirmación como esa puede estar bien para los folletos institucionales del Banco Central, pero es improcedente en un contexto, como el académico, orientado al entendimiento. Quizás el Banco buscará "una” racionalidad económica, quizás no, pero en ningún caso puede ser tenido por el custodio de "la" racionalidad económica. Como sea, el comportamiento del Banco Central responderá a las orientaciones económicas de sus Consejeros, y es ahí donde reside el quid de dicha institución: en la selección de sus integrantes. Más que la súpermayoría, lo que explica las políticas económicas que el Banco Central ha adoptado es el binominalismo -la cultura política surgida como resultado del disciplinamiento del sistema de partidos generada por el sistema electoral binominal-y los consensos económicos amparados por aquel $7^{74}$.

Ahora bien, Verdugo sostiene que "la defensa de las justificaciones especiales depende de la aceptación de un supuesto previo: la necesidad de darle a estos órganos dicha autonomía"75. Incluso concediendo ese supuesto, nuevamente no se divisa en la súper-mayoría una salvaguarda apropiada para la autonomía en cuestión. ¿Es que acaso una súper-mayoría garantiza mayor fidelidad al espíritu de la Constitución? Verdugo podrá aducir que no se trata de eso, sino que de dificultar el comportamiento faccioso aumentando los

${ }^{73}$ Ibíd., p. 425.

${ }^{74}$ Esa es toda la intervención en la conducción del Banco Central que la clase política necesita en el mediano plazo; mal que mal, los consejeros del Banco Central suelen tener una alta vinculación con la clase política, habiendo desempeñado muchos de ellos cargos políticos o funciones de asesoría a legisladores y partidos. Esa cercanía profesional no se da, por ejemplo, en el caso del Poder Judicial. Por ello, la orientación del Banco Central debiera estar en sintonía con las orientaciones económicas de la clase política. En ese contexto, hablar de la "autonomía" del Banco Central es bastante relativo; ciertamente la institución puede tomar decisiones independientemente sin que sean revisables por otra autoridad, pero carece de autonomía cultural, sociológica, disciplinaria o profesional.

${ }^{75}$ Verdugo, S., cit. (n. 1), p. 426. 
costos de transacción. Nuevamente habría que recordarle que eso se logra al costo de aumentar los costos de transacción tanto para el comportamiento faccioso como para el comportamiento virtuoso. Es así como, una vez más, volveremos a la solución adoptada a nivel comparado para este tipo de problemas: un intérprete jurisdiccional de las normas constitucionales habilitado para revisar la conformidad de la legislación con las decisiones constitucionales, en este caso con la decisión sobre la autonomía de los órganos en cuestión.

\section{Congreso Nacional y proceso legislativo.}

$\mathrm{Al}$ reflexionar sobre la "loc." en materia de Congreso y proceso legislativo, Verdugo incurre en el problema observado al comienzo de esta sección: ofrecer como justificaciones específica justificaciones que son, en el mejor de los casos, generales.

¿Qué significa, de hecho, afirmar que la justificación de la "loc." en esta materia es "la importancia de esta materia para el sistema político y legislativo"76? Efectivamente, aquí "la materia es esencialmente importante para el sistema político", y "los principales actores políticos tienen un interés concreto y visible respecto de esta regulación" ${ }^{77}$. ¿Significa que cada vez que haya actores con intereses concretos, éstos debieran ser excluidos de la discusión? Si este fuera el propósito de Verdugo, entonces sería más apropiado entregar la redacción de la Constitución y las principales leyes de procedimiento político a una asamblea constituyente cuyos integrantes quedaran de por vida impedidos de postular a altos cargos públicos. O bien, confiar en una mayor participación de los tribunales en la determinación del proceso legislativo y la resolución de sus conflictos. $O$, incluso más, bastaría -como ocurre en naciones con sistemas constitucionales democráticos- con que la Constitución estableciera ciertos criterios, límites y procedimientos, y que cuando el Presidente tuviese "una mayoría simple y legal en el Congreso" e intentara pasar a "tener el control de la regulación" ", entonces un órgano jurisdiccional le representara sus limitaciones a través del control de constitucionalidad. Tal es, recordemos, la práctica estándar de las democracias constitucionales contemporáneas. ¿Qué necesidad hay aquí de innovar?

\footnotetext{
${ }^{76}$ Ibíd., p. 428.

${ }^{77}$ Ibíd., p. 429.

${ }^{78}$ Ibíd., p. 429.
} 


\section{Conclusiones}

En este artículo hemos criticado la defensa de las "loc.s" que Sergio Verdugo ha ofrecido recientemente. En la sección II, reivindicamos la maciza literatura nacional que las considera ilegítimas e innecesarias y que Sergio Verdugo con demasiada ligereza se ha empeñado en despachar. En la sección III nos referimos detalladamente a los intentos de infructíferos de justificación de las "loc.s" en materias específicas.

Las conclusiones de este artículo son las contrarias a las presentadas por el citado autor. Por un lado, los críticos de las "loc.s" tienen razón al considerar que esta institución es injustificada, al menos en los términos consagrados en nuestra Constitución. En general, en una democracia que se precie ser tal, ella debe ser objeto de un debate democrático en el que se debe demostrar la necesidad de alterar la regla de mayoría. No es aceptable la conveniente estratagema, que Verdugo emplea, de abrazar con todo tipo de artilugios retóricos la ventaja de la legislación de Pinochet. Concluir que hay un equilibrio de razones en torno a la justificación abstracta de las "loc.s", más que una ponderación racional parece un ejercicio de voluntarismo; y concluir que debe discutirse su pertinencia en sectores específicos del ordenamiento jurídico, simplemente no parece convincente.

Por otro lado, Verdugo no aporta a la discusión que -según él, y obviando los argumentos contenidos en la literatura- "aún no hemos tenido con suficiente profundidad" y que es necesario para entender las "loc.s" dentro del sistema constitucional. Cuando se reconoce que la mayoría debe ser la regla general para tomar decisiones legislativas, dado ciertos principios de legitimidad democrática, la carga de argumentar cuál es esa complejidad y por qué la mantención de las "loc.s" es importante para el equilibrio de dicha complejidad, sigue pesando en favor de los defensores de las súper-mayorías y no como falazmente se ha sugerido, en sus críticos.

Esta última conclusión, puede servir para ilustrar la paradoja en que se encuentra un lector atento de su artículo. Por un lado, debe concluir que Verdugo falla en su argumento dado que no logra alterar dicha carga de argumentación. Por otro lado, puede sostenerse que dicha carga se encuentra desde el principio invertida por Verdugo en base al conservador principio que él subscribe, conforme al cual quién desea cambiar un arreglo institucional debe justificar exhaustivamente dicho cambio. El dilema interpretativo al que se enfrenta el lector de su artículo entonces reside en decidir si la defensa de las "loc.s" es una mala defensa, argumentativamente fútil, o es una defensa antidemocrática del régimen heredado de la dictadura.

La afirmación de que "[e]xisten diferentes maneras de orientar el debate 
sobre las leyes org. const., uno general y otro especial [sic]"79, es irrelevante cuando se observa, como se ha mostrado en este artículo, que en las "loc.s" presentan tan dramática falta de justificación democrática. Adicionalmente, la pretendida necesidad de justificación especial de las "loc.s" no es más que otro argumento general respecto a la necesidad de mantener ciertos temas alejados de las mayorías temporales. La pretendida necesidad de justificaciones especiales sólo se transforma en prioritaria cuando se busca la paralización del proceso político democrático.

\section{BiBLIOGRAFÍA}

Ackerman, Bruce, We the People, II: Transformations (Cambridge, Harvard University Press, 1998).

Atria, Fernando, Participación y alienación política: el problema constitucional, en Fuentes, Claudio (editor), Nombre del pueblo: debate sobre el cambio constitucional en Chile (Santiago, Heinrich Böll Stiftung - ConoSur e ICSO Diego Portales, 2010).

Bellamy, Richard, Citizenship. A Very Short Introduction (Oxford University Press, 2008).

Buchanan, James - Tullock, Gordon, The Calculus of Consent. Logical Foundations of Constitutional Democracy (Liberty Fund, 1999).

Correa, Rodrigo, Abuso del Derecho comparado, en El Mercurio, 2 de mayo de 2013.

Correa, Sofía y otros, Historia del siglo XX chileno: balance paradojal (Santiago, Sudamericana, 2001).

Couso, Javier - Coddou, Alberto, Las asignaturas pendientes de la reforma constitucional chilena, en Fuentes, Claudio (editor), en Nombre del pueblo: debate sobre el cambio constitucional en Chile (Santiago, Heinrich Böll Stiftung - ConoSur e ICSO Diego Portales, 2010).

DaHL, Robert, Democracy and its Critics (Yale University Press, 1989).

DAHL, Robert, On Political Equality (Yale University Press, 2006).

De Отто, Ignacio, Derecho constitucional. Sistema de fuentes (Barcelona, Ariel, 1988).

Epstein, David y otros (editores), The future of the Voting Rights Act (New York, Russel Sage Foundation, 2006).

European Commission for Democracy through Law, Opinion on the New Constitution of Hungary [disponible en http://www.venice.coe.int/webforms/ documents/?pdf=CDL-AD(2011)016-e].

FUENTES, Claudio (editor), En nombre del pueblo: debate sobre el cambio constitucional en Chile (Santiago, Heinrich Böll Stiftung-ConoSur e ICSO Diego Portales, 2010).

Goodin, Robert - Lins, Christian, Special Majorities Rationalized [disponible en http:// personal.lse.ac.uk/list/PDF-files/SplMaj1508.pdf].

Habermas, Jurgen, Between Facts and Norms (London, Polity Press, 1996).

LETSAS, George, Two Concepts of the Margin of Appreciation, en Oxford Journal of Legal Studies, 26 (Oxford, 2006) 4.

${ }^{79}$ Ibíd., p. 418. 
Lijphart, A., Constitutional Design for Divided Societies, en Journal of Democracy, 15 (2004).

Marziani, Mimi - Backer, Jonathan - Kasdan, Diana, Curving Filibuster (New York, Brennan Centre of Justice, 2012).

MaY, Kenneth, A Set of Independent Necessary and Sufficient Conditions for Simple Majority Decision, en Econometrica, 20 (1952).

MuÑoz, Fernando, Leyes Orgánico-constitucionales. Insatisfactoria rigidización de la democracia, en Anuario de Derecho Constitucional Latinoamericano, 1 (2006).

Murray, Mimi - Marziani, Digby, Filibuster Abuse (New York, Brennan Centre of Justice, 2012).

Palonen, Emilia, Transition to Crisis in Hungary: Whistle-Blowing on the Naked Emperor, en Politics \& Policy, 40 (2012) 5.

Pastor, Daniel, Origins of the Chilean Binominal Election System, en Revista de Ciencia Politica, 24 (Santiago, 2004).

Post, Robert - Siegel, Reva, Constitucionalismo Democrático. Por una reconciliación entre Constitución y pueblo (Buenos Aires, Siglo XXI, 2013).

Rappaport, Michael - McGinnis, John, Our Supermajoritarian Constitution (San Diego, University of San Diego, Public Law and Legal Theory Working Paper 37).

SADURSKI, Wojciech, Equality and Legitimacy (Oxford, Oxford University Press, 2008).

Schmitt, Carl, Legalidad y legitimidad, en Orestes, Héctor (editor), Carl Schmitt, teólogo de la Politica (Ciudad de México, Fondo de Cultura Económica, 2001).

Shapiro, Ian, The Moral Foundation of Politics (Yale University Press, 2003).

Sierra, Lucas - MAC-Clure Lucas, Frente a las mayorias: leyes supra-mayoritarias y Tribunal Constitucional en Chile (Santiago, Centro de Estudios Públicos, 2011).

Sunstein, Cass, Legal Reasoning and Political Conflict (Oxford, Oxford University Press, 1996).

Sunstein, Cass, The Partial Constitution (Harvard University Press, 1993).

Szmulewicz, Esteban, Democracia, gobierno de la mayoría y leyes orgánicas constitucionales. Parte I (Santiago, Asuntos Públicos, Informe 954, 2012-I) [visible en internet: http://www.asuntospublicos.cl/wp-content/uploads/2012/04/954.pdf].

VERDUGo, Sergio, Las justificaciones de la regla de quórum supra-mayoritaria de las leyes orgánicas constitucionales, en Revista de Derecho de la Pontificia Universidad Católica de Valparaíso, 39 (Valparaíso, 2012).

Verdugo, Sergio, Regla de mayoría y democracia: el caso de las leyes orgánicas constitucionales, en Actualidad Jurídica, 20 (Santiago, 2009), 2.

Vermeule, Adrian, Mechanism of Democracy. Institutional Design Writ Small (Oxford, Oxford University Press, 2007),

Waldron, Jeremy, The Core Case Against Judicial Review, en Yale Law Journal, 115 (2006).

Waldron, Jeremy, The Dignity of Legislation (Cambridge, Cambridge University Press, 1999). 